\title{
Formas de ingresso em perspectiva comparada: por que o SISU aumenta a evasão? O caso da UNB
}

\author{
Entrance systems in comparative perspective:
} why does SISU increase drop out rates? The UNB case

\author{
Andrea Cabello ${ }^{1}$ \\ Denise Imbroisi ${ }^{2}$ \\ Guilherme Alvarez ${ }^{3}$ \\ Guilherme Viana Ferreira ${ }^{4}$ \\ June Arruda 5 \\ Sérgio de Freitas ${ }^{6}$
}

Resumo: O objetivo deste estudo é analisar o impacto das diferentes formas de ingresso sobre a evasão ou desligamento de curso dos alunos da Universidade de Brasília (UnB), ou seja, uma comparação da evasão entre ingressantes pelo SISU, Programa de Avaliação Seriada (PAS) e Vestibular, entre 2014 e 2018. Como metodologia, utilizou-se a taxa de desistência anual e a taxa de desistência acumulada propostas pelo INEP (2017) e concluiu-se que o PAS e o Vestibular têm um padrão semelhante de evasão, com picos no segundo e terceiro ano de trajetória universitária, enquanto o SISU tem uma taxa de desistência consideravelmente superior, e que ocorre mais cedo, com picos nos primeiros anos de curso.

Palavras-chave: Evasão. SISU. Forma de ingresso no ensino superior. 
Abstract: The goal of this study is to analyze the impact of different entry methods on dropout and stop out rates for Universidade de Brasília (UnB)'s students, that is a comparison between dropout rates between those who entered university through SISU, through Programa de Avaliação Seriada (PAS) or through Vestibular, between 2014 and 2018. We used the annual dropout rate and the accumulated dropout rate as proposed by INEP (2017) and we concluded that PAS and Vestibular have similar dropout patterns with peaks in the second and third years of university trajectory, while SISU has a much higher dropout rate, that happens sooner, with peaks in the first year of trajectory.

Keywords: Dropout. SISU. Entry in Higher Education.

${ }^{1}$ Universidade de Brasília Programa de Pós-graduação em Economia | Brasília | DF | Brasil. Contato: andreafc@gmail.com. ORCID: http://orcid.org/0000-0003-1489-0676

${ }^{2}$ Universidade de Brasília Programa de Pós-graduação em Economia | Brasília | DF | Brasil. Contato: imbroisi@unb.br. ORCID: http://orcid.org/0000-0001-5747-5806

${ }^{3}$ Supremo Tribunal de Justiça | Brasília | DF | Brasil. Contato: guilhermeaalvarez@gmail.com. ORCID: http://orcid.org/ 0000-0002-1001-0603

${ }^{4}$ Universidade de Brasília Programa de Pós-graduação em Administração | Brasília | DF | Brasil. Contato: guilhermeviana@gmail.com. ORCID: http://orcid.org/ 0000-0001-8811-0105

${ }^{5}$ Universidade de Brasília Programa de Pós-graduação em Ciência Política | Brasília | DF | Brasil. Contato: june.alves@gmail.com. ORCID: http://orcid.org/0000-0003-2453-9927

${ }^{6}$ Universidade de Brasília Programa de Pós-graduação em Computação Aplicada | Brasília | DF | Brasil. Contato: sergiofreitas@unb.br. ORCID: https://orcid.org/0000-0003-3996-4985

- Recebido em: 17 de junho de 2020

- Aprovado em: 28 de dezembro de 2020

DOI: http://dx.doi.org/10.1590/S1414-40772021000200006

Este é um artigo publicado em acesso aberto sob uma licença Creative Commons https://creativecommons.org/licenses/by-nc/4.0/ 


\section{Introdução}

A avaliação de políticas de Educação Superior pode ser feita de diversas formas e uma delas é por indicadores quantitativos que mensuram o sucesso dos alunos ao longo de sua trajetória acadêmica. Isso pode ser contabilizado, por exemplo, por índices construídos com base no número de diplomados, uma vez que se espera que uma trajetória bem-sucedida se encerre com a diplomação.

Dessa forma, pesquisas sobre os determinantes da desistência, permanência, retenção, evasão e formatura têm ganhado importância no Brasil. Apesar disso, é um tema que ainda carece de estudos quantitativos cuidadosos que definam metodologias de maneira adequada (CABELLO et al., 2018a; CUNHA; TUNES; SILVA, 2001; SANTOS JUNIOR; REAL, 2017) e de análises que discutam as razões para o (in)sucesso nessa trajetória (CUNHA; TUNES; SILVA, 2001). Há, por exemplo, trabalhos que mensuram os índices de evasão a partir de dados agregados, como Veloso e Almeida (2001), Silva Filho et al. (2007) e Ambiel (2015), além de pesquisas que optam pelo acompanhamento da trajetória discente, realizando uma análise longitudinal, como em Massi e Villani (2015).

O próprio conceito de evasão não é consensual. A Comissão Especial de Estudos sobre a Evasão nas Universidades Públicas Brasileiras (BRASIL, 1996) define três tipos de evasão: 1) desligamento do curso, mas permanência na instituição; 2) desligamento da instituição, mas permanência no sistema; e 3) desligamento do sistema com o abandono definitivo ou temporário do ensino superior.

O estudo realizado pelo Ministério da Educação por meio da Comissão Especial de Estudos sobre Evasão nas Universidades Públicas Brasileiras (BRASIL, 1996) é considerado seminal e aponta causas que ainda hoje são mencionadas em obras mais recentes (SCHARGEL; SMINK, 2002; GAIOSO, 2006; GILLIOLI, 2016), como por exemplo características individuais dos alunos e fatores internos e externos às instituições.

A unificação do processo seletivo torna a questão da evasão ainda mais complexa. Em processos individuais, como o vestibular de uma única universidade, a instituição é escolhida previamente pelo candidato, ou seja, se o candidato pagou a taxa de inscrição e realizou todas as etapas do processo de avaliação e seleção, ele já revelou que está disposto, pelo menos em princípio, a estudar naquela instituição. Já em processos unificados, temos um maior acesso de candidatos de baixa renda que não poderiam participar de tantos processos seletivos. Sua escolha pode ser condicionada não a uma preferência prévia e pensada de acordo com suas restrições financeiras - local de moradia, alimentação, interesses etc. - mas sim pelo seu 
desempenho na prova, já que o candidato pode vir a escolher a opção em que ele conseguiu passar.

As consequências dessa escolha estratégica são as mais diversas: escolhas feitas sem considerar os custos de mudança de domicílio podem levar a baixas taxas de comparecimento em registro; a mudança de curso ou de opção após o ingresso também é um fator a ser considerado, pois uma vez selecionado e registrado, o agora aluno sabe que pode escolher não permanecer naquele curso por muito tempo, apesar de manter-se na instituição. Nesse último caso ele teria utilizado o processo seletivo apenas para ingressar na instituição para depois fazer uma mudança de curso.

O objetivo deste estudo é analisar o impacto da forma de ingresso sobre a evasão ou desligamento de curso dos alunos da Universidade de Brasília (UnB). O caso da UnB é de particular interesse, dado que a instituição tem, até 2019, três principais formas de ingresso primário diferentes, a saber: i) o Programa de Avaliação Seriada (PAS), em que o candidato realiza três provas, em cada etapa de seu Ensino Médio, e sua avaliação e seleção ocorre de acordo com seu escore final calculado a partir da nota nessas três provas. Somente candidatos cursando o Ensino Médio em três anos subsequentes, sem interrupção, podem utilizar essa forma de ingresso. Inicialmente, o PAS selecionava candidatos somente para ingresso no primeiro semestre letivo do ano acadêmico. Atualmente, a seleção é feita tanto para o ingresso no primeiro quanto para no segundo semestre. Outra modificação recente foi a possibilidade de o candidato alterar sua opção de curso após descobrir seu escore final, sendo válida a sua última escolha, em um sistema semelhante à troca de opção do SISU; ii) O Vestibular, forma de ingresso tradicional da maior parte das universidades no Brasil, em que o candidato realiza uma prova após a escolha do curso para o qual concorre. Atualmente, o Vestibular da UnB seleciona alunos somente para o ingresso no segundo semestre letivo. A troca de opção também é permitida no Vestibular, em 2019 iii) O SISU, forma organizada diretamente pelo Ministério da Educação, em que o candidato faz a prova do Exame Nacional do Ensino Médio (ENEM) e, após saber sua nota nessa prova, candidata-se a vagas em universidades públicas em todo o país, por meio do sistema unificado de Educação Superior. O candidato pode listar até duas opções de curso/turno/campus/instituição e pode alterar essas opções ( $1^{\mathrm{a}}$ e $2^{\mathrm{a}}$ opções) várias vezes durante uma janela de troca, sendo considerada válida a última escolha do candidato registrada no sistema ${ }^{1}$.

\footnotetext{
${ }^{1}$ Em decisão de junho de 2019, a UnB optou por não mais adotar o SISU, nem permitir no PAS e no Vestibular a troca de opção registrada pelo candidato quando de sua inscrição. A Universidade permanecerá com três formas 
Trata-se, portanto, de formas de ingresso distintas, com provas construídas de formas diferentes (por exemplo, no PAS a prova é seriada, com acompanhamento e feedback ao aluno e no Vestibular e Enem há uma prova única de seleção) e custos diferentes para as instituições participantes. Neste artigo, a partir do estudo de caso da UnB, avaliam-se as consequências da adoção de cada uma das três formas de ingresso sobre a taxa de desistência dos alunos nas Instituições de Ensino Superior.

A forma de ingresso pode levar à seleção de alunos com perfis diferentes e, por isso, com desempenhos diferentes. Nesse sentido, a pergunta de pesquisa que se faz é: i) a forma de ingresso utilizada pela UnB afeta o desempenho de seus alunos, mensurado pela sua taxa de desistência? Caso encontremos evidências de que não se possa descartar um possível efeito da forma de ingresso sobre a taxa de desistência, colocamos uma segunda pergunta: ii) qual, dentre as formas de ingresso utilizadas pela $\mathrm{UnB}$, tem maior efeito negativo sobre o desempenho acadêmico dos seus alunos, mensurado pela taxa de desistência?

Essas questões se justificam por, pelo menos, três motivos: i) o SISU difere dos outros modelos de forma de ingresso por se tratar de um sistema centralizado, em que o estudante se candidata a várias instituições do país em um único processo. Isso reduz os custos financeiros e logísticos de se candidatar a instituições longe de casa, por exemplo, suscitando o debate sobre a mobilidade estudantil, mas dificultando a permanência do estudante se ele ingressar em uma instituição distante; por isso, o debate acerca da evasão; ii) ao permitir que o candidato modifique sua escolha de curso/turno/campus/instituição, o SISU permite a chamada escolha estratégica, em que o candidato pondere de forma mais intensa o desejo de ingressar na universidade em qualquer instituição, em qualquer curso frente a sua escolha preferida de curso e instituição, mas inalcançável naquele processo seletivo devido ao seu desempenho na seleção. Essa possibilidade pode gerar tanta evasão de curso - quando o curso não é o preferido, mas a instituição o é -, quanto da própria instituição; iii) o SISU permite que o candidato liste duas opções - uma primeira, supostamente preferida e uma segunda, caso não seja selecionado em sua primeira opção. Essa possibilidade faz com que o candidato concorra em mais de um curso em uma instituição ou para um mesmo curso em mais de uma instituição - é inteiramente livre a combinação das primeiras e segunda opções. Isso pode fortalecer também a escolha estratégica mencionada no item ii. Esses efeitos se somam aos já observados na literatura quanto às demais causas de evasão de curso, de uma instituição ou do sistema.

de ingressos distintos PAS, Vestibular e ENEM e três provas diferentes. As notas do Enem serão utilizadas pela própria UnB para elaborar a listagem com a classificação dos candidatos nos cursos/turnos/campus pretendidos. 
Este artigo se divide em três seções, além dessa introdução. A primeira seção aborda referências sobre o tema disponíveis na literatura científica, enquanto a segunda seção discute nossa metodologia e apresenta resultados. Por fim, a terceira e última seção traz os comentários finais.

\section{Fundamentação teórica}

Há diversos estudos que se debruçam sobre os efeitos da adoção de diferentes formas de ingresso sobre a evasão. Esses estudos ganharam importância e volume na última década devido à adoção do SISU, que possibilitou: i) a comparação, na maior parte das instituições, de dois sistemas simultâneos de ingresso diferentes; ii) a percepção de resultados diferentes relacionados a algumas variáveis, principalmente, a ocupação de vagas, a mobilidade estudantil e a evasão.

Alguns desses estudos analisam os efeitos sobre cursos ou instituições específicas, enquanto outros fazem análises comparativas ou considerando o sistema como um todo (BARBOSA et al., 2017; COSTA, 2012; GÓMEZ; TORRES, 2015). Gillioli (2016) talvez apresente, até o momento, a mais extensa revisão de literatura sobre os efeitos do SISU na evasão universitária. Ariovaldo e Nogueira (2018) fazem uma revisão da literatura sobre o tema comparando métodos e objetivos. Na opinião desse autor, não há consenso acerca dos efeitos do SISU sobre a evasão - talvez uma afirmativa de falta de consenso seja muito forte, a nosso ver: há evidências fortes sim, apontadas pela maior parte da literatura, quando métodos estatísticos robustos são considerados, mas mais estudos são necessários para entender melhor o problema ${ }^{2}$.

Em relação ao efeito sobre as taxas de ocupação de vagas ou taxas de comparecimento em registro, Gillioli (2016) discute a questão para o Sistema de Educação Superior como um todo, tendo em vista as diversas chamadas do SISU e a grande ociosidade de vagas. Nogueira et al. (2017) também reportam o problema na UFMG. Na UnB, enquanto o PAS e o Vestibular apresentam, em geral, taxas de ocupação de vagas superiores a 90\% já na primeira chamada, há dificuldades de se preencher todas as vagas oferecidas pelo SISU ao longo das diversas chamadas, sendo que as taxas de comparecimento em primeira chamada estão em torno de 50-

\footnotetext{
${ }^{2}$ Ele cita o trabalho de Gómez e Torres (2015) como exemplo de queda de taxa de evasão na UTFPR, mas essa queda é atribuída a programas de assistência estudantil e não à adoção do SISU.
} 
$60 \%^{3}$, principalmente em alguns cursos específicos, de forma consistente com o observado na literatura ${ }^{4}$.

Em relação ao efeito sobre a mobilidade estudantil, Li (2016) mensurou os efeitos do SISU sobre a migração estudantil, concluindo que essa forma de ingresso aumenta a possibilidade de migração interestadual. Szerman (2015) também mensurou efeitos que reforçam a noção do SISU como um mecanismo de mobilidade estudantil. No entanto, Nogueira et al. (2017) observam efeitos modestos em relação à mobilidade estudantil na UFMG - houve aumento do número de inscritos, mas não o percentual de matriculados. Gillioli (2016) e Gómez e Torres (2015) também chamam a atenção para efeitos regionais. No caso da UnB, Cabello e Rodrigues (2018) e Cabello et al. (2018b) observaram que não há indícios de modificações significativas no padrão de origem dos alunos matriculados da UnB nos últimos 15 anos - menos de 5\% dos alunos são oriundos de regiões fora do Distrito Federal e regiões de seu Entorno, sugerindo a realização de mais estudos, mas sinalizando que possivelmente a situação seria similar à encontrada na UFMG.

Em relação à evasão, Barbosa et al. (2017) analisando o caso da UFU, observaram aumento não tão grande em termos agregados na evasão com a adoção do SISU, mas considerável em alguns cursos, principalmente da área de Exatas. Como dito anteriormente, Gillioli (2016) conclui pela ausência de um consenso na literatura, dizendo que fatores específicos são exacerbados quando o SISU é adotado - em suas palavras: "O SISU só é elemento que aumenta a evasão se conjugado a outros fatores que eventualmente contribuam nesse sentido, não sendo, desta feita, variável isoladamente responsável pelo fenômeno" ( $\mathrm{p}$. 44). Ele ressalta, no entanto que, em algumas instituições, há uma nota mínima que deve ser alcançada no ENEM para o aluno ser selecionado. Isso favoreceria a evasão, pois candidatos que têm preferência por esses cursos, mas não têm nota suficiente, optam por cursos menos concorridos e acabam mais suscetíveis à evasão.

Li (2016) observa uma maior probabilidade de evasão da instituição no primeiro ano e maior probabilidade de mudança para outro curso da mesma universidade, efeito também percebido por Nogueira et al. (2017). Szerman (2015) também observou efeitos significativos de evasão da instituição e os associou ao comportamento estratégico dos alunos - esse comportamento também é mencionado por Ariovaldo e Nogueira (2018).

\footnotetext{
${ }^{3}$ Fonte: Decanato de Ensino de Graduação - UnB.

${ }^{4} \mathrm{O}$ uso de chamadas públicas com o objetivo de preenchimento de vagas ociosas por algumas instituições tem se tornado cada vez mais comum também.
} 
Li (2016) e Gillioli (2016) chamam a atenção para o papel de programas de assistência estudantil, que mitigariam os efeitos da evasão principalmente da instituição, mas não de curso. O perfil do candidato afeta a escolha do processo seletivo pelo candidato. Por exemplo: alunos mais velhos se inscreveriam nos vestibulares, enquanto o SISU, por utilizar o ENEM, teria um viés que favoreceria alunos mais novos. No caso da UnB, deve-se considerar que o PAS é limitado a egressos do Ensino Médio do ano corrente - não se tratando apenas de um viés e sim de uma restrição.

\section{Metodologia e resultados}

As estatísticas apresentadas foram calculadas com base na nota técnica do INEP (2017), que utiliza indicadores de trajetória, buscando fazer o acompanhamento de uma turma, ou coorte, desde seu ingresso na universidade, durante o tempo previsto de curso até o final do seu tempo de acompanhamento, atualmente definido como duas vezes o tempo previsto de curso.

Os dados foram extraídos do Sistema de Gestão de Cursos de Graduação da UnB SIGRA-UnB - em setembro de 2018 e referem-se ao período de 2014 a 2017. Escolheu-se esse período devido à implantação do sistema SISU na UnB, em 2014, permitindo a comparação entre os três sistemas para uma mesma coorte. Dessa forma, todas as coortes consideradas apresentam grande número de alunos ainda ativos, de modo que principalmente as taxas consolidadas devem ser consideradas como dinâmicas, no sentido que podem ser modificadas pela própria trajetória, em andamento, dos alunos que as compõem.

O principal indicador a ser utilizado será a taxa de desistência anual, que pode ser definida como o percentual de alunos desistentes do curso por ano, que pode ocorrer tanto por mudança para outro curso da UnB, não sendo uma evasão da UnB, quanto desistência da UnB, algo que o indicador como apresentado aqui não distingue. $\mathrm{O}$ indicador não permite também inferir as causas da desistência; entretanto, desistências em momentos diferentes do curso (por exemplo, uma desistência no primeiro ano frente a uma desistência no terceiro ano) têm, provavelmente, causas distintas, assim como desistências em cursos diferentes podem ter causas distintas.

Atualmente, considerando as principais formas de ingresso primário na UNB por semestre letivo, no primeiro semestre do ano, a seleção é feita com base no PAS e no SISU, e no segundo semestre do ano ela é feita com base no PAS e no Vestibular. Até 2016, o Vestibular era a principal forma de ingresso da universidade, selecionando cerca de 4 mil alunos anualmente, enquanto o SISU e o PAS selecionavam pouco menos de 2 mil alunos cada. A 
partir de 2017, o número de vagas para o PAS e o Vestibular assumiu a configuração atual: para o primeiro semestre letivo, um pouco mais de 2 mil vagas são oferecidas ao SISU e igual quantitativo ofertado à seleção do PAS para ingresso no primeiro semestre; para o segundo semestre letivo, pouco mais de 4 mil vagas são oferecidas distribuídas proporcionalmente entre Vestibular e PAS de segundo semestre.

Conforme observado na seção anterior, a literatura considera três efeitos principais ociosidade de vagas, mobilidade estudantil e evasão - quando compara o SISU a processos tradicionais. $\mathrm{Na} \mathrm{UnB}$, a ociosidade de vagas pode ser mensurada por duas formas: i) a já mencionada diferença na taxa de comparecimento de registro, em que o PAS e o Vestibular apresentam taxas geralmente superiores a $90 \%$ já em primeira chamada e o SISU taxas de comparecimento em primeira chamada de cerca de 50-60\%; e ii) a diferença na taxa de anulação de registro entre as três formas de ingresso, apresentada no Gráfico 1, que apresenta o percentual de anulação de registro por forma de ingresso e ano de ingresso em relação ao total de vagas ofertada por cada forma de ingresso em cada ano. Em relação à mobilidade estudantil, já mencionamos estudos para UnB que indicam que a presença de alunos de outros estados nessa instituição ainda é limitada, mesmo após a adoção do SISU.

\section{Gráfico 1 - Percentual de Anulação de Registro por Forma de Ingresso e Ano de Ingresso}

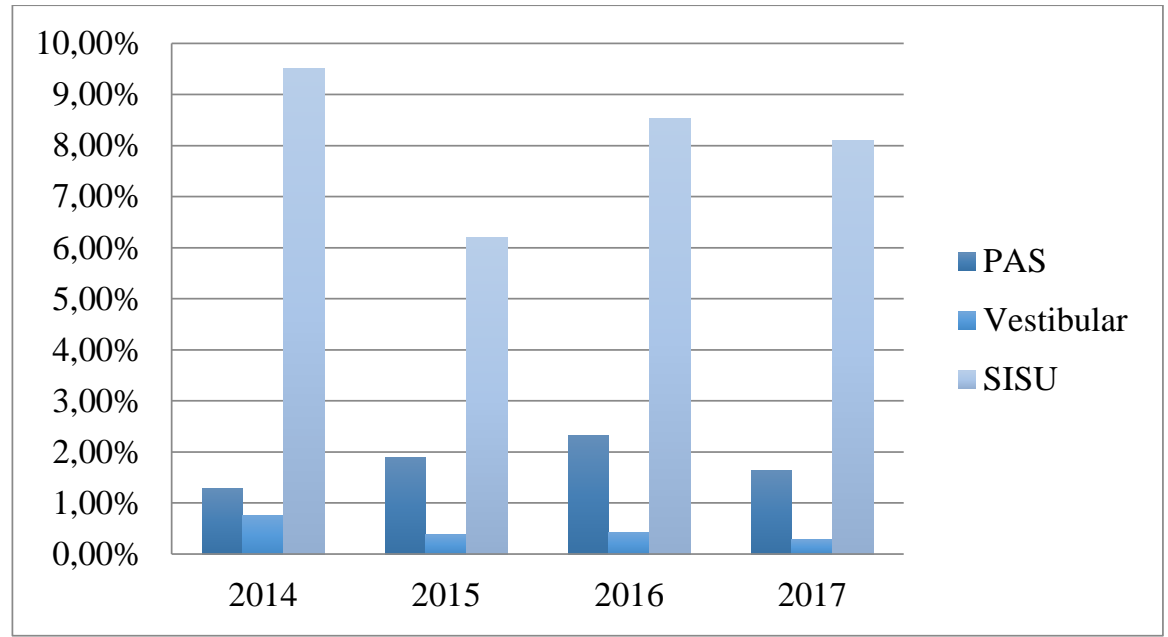

Fonte: Elaboração Própria com base nos dados do SIGRA-UnB. Extração: fevereiro de 2018.

O Gráfico 1 mostra um comportamento próximo das taxas de anulação de registro para estudantes que ingressaram por meio de PAS e de Vestibular e taxas de anulação de registro anuais médias muito mais altas para os de SISU. As taxas do primeiro ano para o Vestibular são menores pois, como sua seleção é feita somente para o segundo semestre letivo, o primeiro ano completo desses alunos está deslocado entre o primeiro e o segundo anos de trajetória na 
universidade. Tal diferença se traduz em uma taxa de anulação de registro um pouco superior para o segundo ano, mas não tem efeitos finais significativos sobre a taxa acumulada ao longo da trajetória.

Os próximos gráficos mostram a comparação entre as formas de ingresso considerando a taxa de desistência por ano, tanto desagregada para cada uma das turmas, quanto a média dessas taxas desagregadas, para facilitar a comparação geral entre as formas de ingresso. $\mathrm{O}$ Gráfico 2 mostra a Taxa de Desistência Anual Média por Forma de Ingresso na UnB entre 2014 e 2017.

Gráfico 2 - Taxa de Desistência Anual Média por Forma de Ingresso na UnB entre 2014 e $2017 \underline{5}$

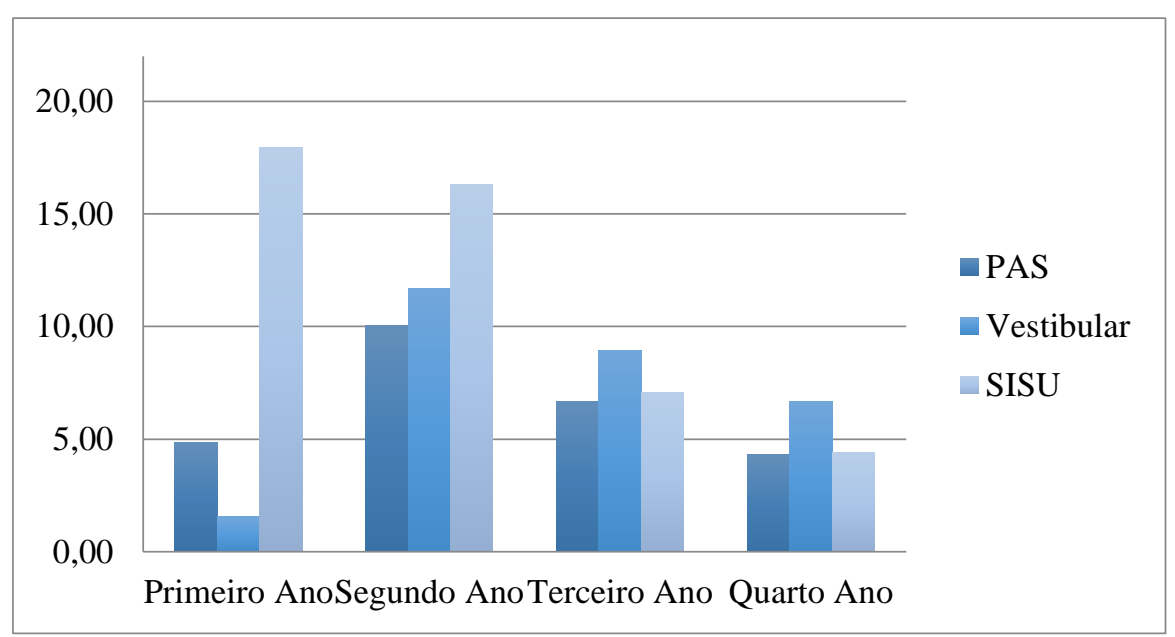

Fonte: Elaboração Própria com base nos dados do SIGRA-UnB. Extração: setembro de 2018.

O Gráfico 2 mostra um comportamento próximo entre o PAS e o Vestibular e taxas de desistência anuais médias muito mais altas para o SISU. As taxas do primeiro ano para o Vestibular são menores pois, como sua seleção é feita somente para o segundo semestre letivo, o primeiro ano desses alunos está deslocado entre o primeiro e o segundo anos de trajetória na universidade. Tal diferença se traduz em uma taxa de desistência um pouco superior para o segundo ano, mas não tem efeitos finais significativos sobre a taxa acumulada ao longo da trajetória.

O Gráfico 3 mostra as taxas de desistência acumuladas para cada forma de ingresso até o final do período considerado. Nesse caso, para a coorte de 2014, é uma taxa ao final do quarto ano de trajetória; para a coorte de 2015, refere-se à taxa ao final do terceiro ano de trajetória;

\footnotetext{
${ }^{5}$ Como o quarto ano se trata de apenas uma observação, não é uma média e sim o valor observado de fato para a coorte de 2017 ao final de 2017. Para os outros anos, o Primeiro Ano é a média das coortes de 2014 a 2017; o Segundo Ano é a média das coortes de 2015 a 2017; e o Terceiro Ano é a média das coortes de 2016 e 2017.
} 
enquanto para a coorte de 2016, refere-se à taxa ao final do segundo ano de trajetória; e, por fim, para a coorte de 2017, refere-se à taxa ao final do primeiro ano de trajetória.

Gráfico 3 - Taxa de Desistência Acumulada por Forma de Ingresso na UnB entre 2014 e 2017

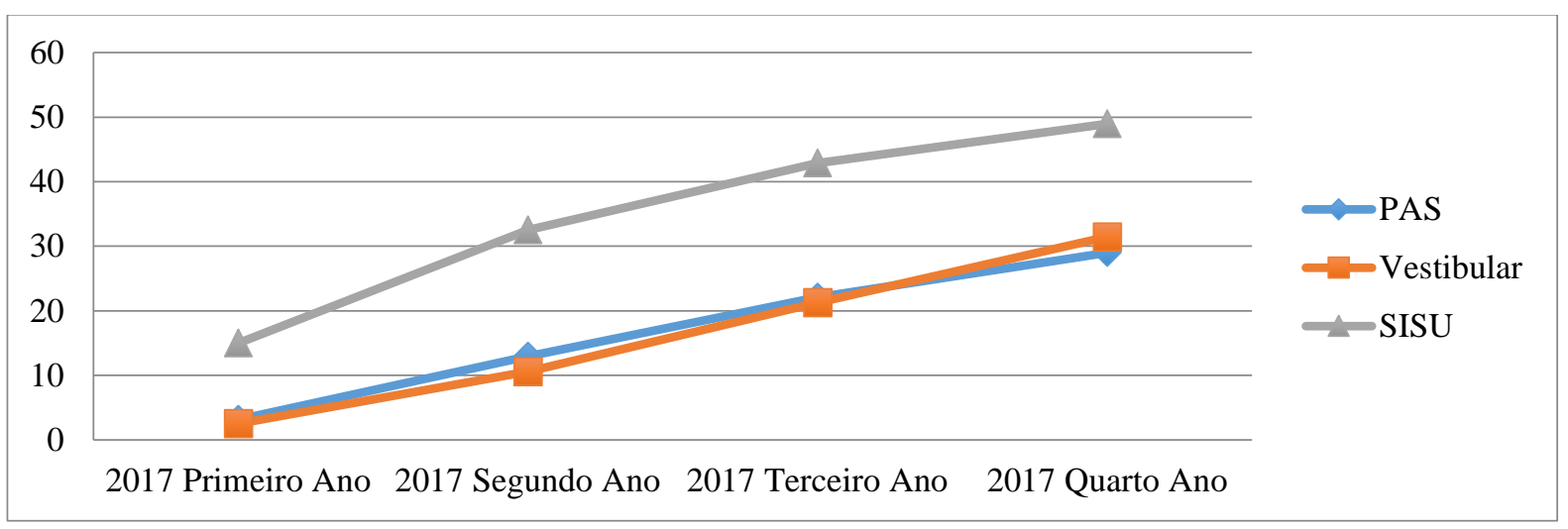

Fonte: Elaboração própria com base nos dados do SIGRA-UnB. Extração: setembro de 2018.

O gráfico 3 reforça os indícios do gráfico 2 de que o PAS e o Vestibular apresentam um comportamento semelhante e que o SISU leva a taxas de desistência muito superiores.

Os gráficos 2 e 3 chamam a atenção para o fato de que, para o SISU, a taxa de desistência anual no primeiro ano é três vezes maior que a maior taxa tanto do PAS quanto do Vestibular. Em outras palavras, o problema de permanência e desligamento dos alunos do SISU ocorre assim que o aluno ingressa na universidade. Esse efeito perdura no segundo ano, quando a discrepância entre essas taxas para o SISU e os dois sistemas se reduz um pouco, mas ainda é acentuada.

É de se esperar que as taxas de desistência do segundo ano e possivelmente do terceiro ano sejam as mais altas da trajetória de uma coorte. Isso ocorre pois é o momento em que o estudante enfrenta dificuldades acadêmicas que se acumularam desde seu ingresso, como reprovações e uma consequente retenção. Além disso, a escolha inadequada de curso, quando ocorre, também se torna mais clara nesse momento, após um primeiro ano de experiência acadêmica.

As taxas de desistência entre as formas de ingresso assumem valores semelhantes somente no terceiro ano da trajetória da coorte. Observa-se também que nesse mormente, é a primeira vez também que outro processo seletivo, nesse caso, o Vestibular, tem taxa de desistência anual superior as observadas para o SISU.

Verifica-se, portanto, que as taxas de desistência acumuladas tão mais altas para o SISU, como as evidenciadas no Gráfico 3, ocorrem não por questões que se desenvolvem ao longo da trajetória dos alunos e sim por problemas presentes logo após o ingresso, no primeiro e segundo 
ano de trajetória. Dessa forma, a relação desses problemas com a forma de ingresso parece, a princípio, bastante robusta.

Assim, conclui-se que, o SISU, como forma de ingresso: i) apresenta maior dificuldade para preenchimento das vagas ofertadas, o que é evidenciado pelo baixo comparecimento dos selecionados em registro de matrícula e pela subsequente anulação do registro, quando o candidato opta por outra instituição ${ }^{6}$; ii) apresenta maiores taxas de desistência nos primeiro ${ }^{7}$ e segundo anos para aqueles alunos que de fato se registram e se matriculam, o que sugere dificuldades de permanência desses alunos. No entanto, no terceiro e quarto anos da trajetória do estudante, as diferenças nas taxas de desistência entre os três processos seletivos desaparecem, sugerindo que os alunos selecionados pelo SISU e que de fato permanecem não teriam, a princípio, um perfil diferente dos demais. Ou seja, o aumento da evasão relacionado ao SISU em relação aos demais processos não parece ocorrer por aspectos acadêmicos dos estudantes selecionados e sim por questões relacionadas à permanência e à opção de curso, sendo consistentes com os achados da literatura favoráveis a ações de assistência estudantil, por exemplo.

No entanto, essas conclusões nos levam a um questionamento que a literatura ainda não pode solucionar: o motivo pelo qual o SISU causa um aumento nessa evasão inicial e porque ele induz à escolha estratégica de curso. Qual dos seus componentes é o responsável por essa dinâmica? É o fato de ser um processo seletivo unificado; de permitir a troca de escolha após conhecer seu desempenho no processo; ou por permitir ao candidato a inclusão de uma primeira e segunda opções em um mesmo processo seletivo, que podem inclusive ser em instituições localizadas em cidades e estados diferentes?

A análise contrafactual dessas questões é, no mínimo, desafiadora. No entanto, os processos de ingresso primário da UnB permitem uma comparação interessante: o PAS e o Vestibular não são um processo seletivo unificado e nem permitem ao candidato a inclusão de uma primeira e segunda opções em um mesmo processo seletivo. No entanto, o PAS e o Vestibular, de maneira similar (mas não idêntica) ao SISU, permitem a mudança de opção após informação acerca do desempenho. Apesar dessa possibilidade, o padrão de ociosidade de vagas e evasão do PAS e do Vestibular sugeriram que, mesmo que esse efeito ocorra, ele é dominado pelo efeito das outras características. Dessa forma, entende-se que o componente SISU é responsável pelo aumento da ociosidade de vagas e evasão. Nossos resultados sugerem uma

\footnotetext{
${ }^{6}$ Conforme observado de forma ampla na literatura.

${ }^{7} \mathrm{Li}$ (2016) havia observado esse efeito para o primeiro ano.
} 
investigação mais aprofundada sobre o caráter centralizado do processo do SISU e a possibilidade de múltiplas opções.

\section{Conclusão}

O objetivo desse artigo foi discutir as consequências sobre a taxa de desistência de estudantes das três diferentes formas de ingresso na UnB. Em consonância com a literatura, observou-se um aumento na ociosidade de vagas e evasão mensurada pela taxa de desistência para o ingresso por meio do SISU.

Esse aumento na taxa de desistência no SISU ocorre principalmente nos dois primeiros anos de curso, de tal forma que seu padrão, a partir do terceiro ano, se assemelha às duas outras formas de ingresso primário da instituição: PAS e Vestibular. Dessa forma, o aumento da evasão relacionado ao SISU em relação aos demais processos não parece ocorrer por questões acadêmicas dos selecionados, estando relacionadas à permanência na instituição e ao curso escolhido pelo estudante.

Evidenciou-se que, para a UnB, o SISU não somente oferece baixo comparecimento em matrículas, mas apresenta maior desistência nos primeiros dois anos de trajetória universitária. Dessa forma, sugere-se que possa ocorrer uma evasão causada por motivos diferentes, uma vez que aqueles que permanecem se comportam de modo similar aos demais processos seletivos.

Como questionamentos futuros para pesquisa, há necessidade de se investigar de forma mais aprofundada os motivos pelo quais ocorre diferença na permanência nesses primeiros dois anos de curso para as diferentes formas de ingresso. Nesse sentido, de modo a desenvolver um contrafactual capaz de responder essa questão, sugere-se o desenvolvimento de um experimento capaz de isolar cada um desses mecanismos, de forma comparativa.

\section{Referências}

AMBIEL, R. Construção da escala de motivos para evasão do ensino superior. Avaliação Psicológica: Interamerican Journal of Psychological Assessment, Itatiba, v. 14, n. 1, p. 41-52, 2015. Disponível em: https://www.redalyc.org/pdf/3350/335042985006.pdf. Acesso em: 10 maio 2020.

ARIOVALDO, T.; NOGUEIRA, C. Nova forma de acesso ao ensino superior público: um estado do conhecimento sobre o Sistema de Seleção Unificada-SISU. Revista Internacional de Educação Superior, Campinas, v. 4, n. 1, p. 152-174, jan./abr. 2018. Disponível em: https://periodicos.sbu.unicamp.br/ojs/index.php/riesup/article/view/8650683. Acesso em: 10 maio 2020. 
BARBOSA, J. et al. A adoção do SISU e a evasão na Universidade Federal de Uberlândia. Revista Ibero-Americana de Estudos em Educação, Araraquara, v. 12, n. 2, p. 708-721, 2017. Disponível em: https://periodicos.fclar.unesp.br/iberoamericana/article/view/8352. Acesso em: 10 maio 2020.

BRASIL. Ministério de Educação e Cultura. Secretaria de Ensino Superior. Comissão Especial de Estudos sobre a Evasão nas Universidades Públicas Brasileiras. Brasília: ANDIFES/ABRUEM/SESu/MEC, 1996.

CABELLO, A. et al. Evasão no ensino superior: qual metodologia adotar? Uma análise sobre o efeito de diferentes metodologias para a identificação de índices de evasão no ensino superior brasileira. In: COLÓQUIO INTERNACIONAL DE GESTÃO UNIVERSITÁRIA, 18., 2018, Loja. COLÓQUIO INTERNACIONAL DE GESTÃO UNIVERSITÁRIA, 18., 2018, Loja. Anais [...]. Loja, Ecuador, 2018a. Disponível em:

https://repositorio.ufsc.br/bitstream/handle/123456789/191468/101_00150.pdf?sequence=1. Acesso em: 10 maio 2020.

CABELLO, A. et al. A garantia da qualidade na gestão do ensino superior: desafios, desenvolvimentos e tendências. In: CONFERÊNCIA DA ASSOCIAÇÃO FORGES, 8., 2018, Lisboa, Portugal. Anais [...]. Lisboa, Portugal, 2018b.

CABELLO, A.; RODRIGUES, R. Universidade pública e desenvolvimento local: análise da dispersão geográfica dos ingressantes na UnB de 2002 a 2015. In: COLÓQUIO

INTERNACIONAL DE GESTÃO UNIVERSITÁRIA, 18., 2018, Loja. Anais [...]. Loja, Ecuador, 2018. Disponível em:

https://repositorio.ufsc.br/bitstream/handle/123456789/190512/101_00145.pdf?sequence=1. Acesso em: 10 maio 2020.

COSTA, Anna Regina C. Impactos da adoção do SiSU como instrumento de acesso aos cursos de graduação: análise preliminar nos cursos de Engenharia do Cefet/RJ UnED NI. In: CONGRESSO NACIONAL DE MATEMÁTICA APLICADA E COMPUTACIONAL, 34. , 2018, Águas de Lindoia. Anais [...]. Águas de Lindoia, SP, 2012. Disponível em: http://sbmac.locaweb.com.br/eventos/cnmac/xxxiv_cnmac/pdf/18.pdf. Acesso em: 10 maio 2020.

CUNHA, A.; TUNES, E.; SILVA, R. Evasão do curso de Química da Universidade de Brasília: a interpretação do aluno evadido. Química Nova, São Paulo, v. 24, n. 2, p. 262-280, mar./abr. 2001. Disponível em: https://www.scielo.br/scielo.php?pid=S010040422001000200019\&script=sci_arttext\&tlng=pt. Acesso em: 10 maio 2020.

GAIOSO, N. O fenômeno da evasão escolar na educação superior no Brasil. Dissertação (Mestrado em Educação) - Universidade Católica de Brasília, Brasília, 2006.

GILLIOLI, R. Evasão em instituições federais de ensino superior da rede, SISU e desafios. Brasília: Consultoria Legislativa Câmara dos Deputados, maio 2016. Estudo Técnico. Disponível em:

https://nupe.blumenau.ufsc.br/files/2017/05/evasao_institui\%C3\%A7\%C3\%B5es.pdf. Acesso em: 10 maio 2020. 
GÓMEZ, M. R. F.; TORRES, J. Discutindo o acesso e a permanência no ensino superior no contexto do SiSU (Sistema de Seleção Unificada). Org \& Demo, Marília, SP, v. 16, n. 1, p. 69-88, jan./jul. 2015. Disponível em:

https://revistas.marilia.unesp.br/index.php/orgdemo/article/view/5162. Acesso em: 10 maio 2020.

INEP. Metodologia de cálculo dos indicadores de fluxo da educação superior. Brasília, 2017. Nota técnica. Disponível em:

http://download.inep.gov.br/informacoes_estatisticas/indicadores_educacionais/2017/metodol ogia_indicadores_trajetoria_curso.pdf. Acesso em: 10 maio 2020.

LI, D. O novo ENEM e a plataforma SiSU: efeitos sobre a migração e a evasão estudantil. Tese (Doutorado em Economia) - Universidade de São Paulo, São Paulo, 2016. Disponível em: https://www.teses.usp.br/teses/disponiveis/12/12138/tde-23112016-

094256/publico/CorrigidaDenise.pdf. Acesso em: 10 maio 2020.

MASSI, L.; VILLANI, A. Um caso de contratendência: baixa evasão na licenciatura em química explicada pelas disposições e integrações. Educação e Pesquisa, São Paulo, v. 41, n. 4, p. 975-992, dez. 2015. Disponível em: https://repositorio.unesp.br/handle/11449/157783. Acesso em: 10 maio 2020.

NOGUEIRA, C. et al. Promessas e limites: o SISU e sua implantação na Universidade Federal de Minas Gerais. EDUR - Educação em Revista, Belo Horizonte, n. 33, 2017.

SANTOS JUNIOR, J.; REAL, G. A evasão na educação superior: o estado da arte das pesquisas no Brasil a partir de 1990. Avaliação, Campinas; Sorocaba, v. 22, n. 2, p. 385-402, ago. 2017. Disponível em: https://www.scielo.br/scielo.php?pid=S141440772017000200385\&script=sci_abstract\&\%20tlng=pt. Acesso em: 10 maio 2020.

SCHARGEL, F.; SMINK, J. Estratégias para auxiliar o problema de evasão escolar. Rio de Janeiro: Dunya, 2002. Disponível em: https://www.scielo.br/scielo.php?pid=S010246982017000100116\&script=sci_arttext. Acesso em: 10 maio 2020.

SILVA FILHO, Roberto Leal Lobo et al. A evasão no ensino superior brasileiro. Cadernos de Pesquisa, São Paulo, v. 37, n. 132, p.641-659, dez. 2007. Disponível em: https://www.scielo.br/scielo.php?pid=S010015742007000300007\&script=sci_arttext\&tlng=pt. Acesso em: 10 maio 2020.

SZERMAN, C. The effects of a centralized college admission mechanism on migration and college enrollment: evidence from Brazil. Dissertação (Mestrado em Economia) Fundação Getúlio Vargas, Rio de Janeiro, 2015.

VELOSO, T. C. M. A.; ALMEIDA, E. P. de. Evasão nos cursos de graduação da Universidade Federal de Mato Grosso, campus universitário de Cuiabá: um processo de exclusão. In: REUNIÃO ANUAL DA ANPEd, 24., 2001, Caxambu, MG. Anais [...]. Caxambu: ANPEd, 2001. Disponível em: https://www.serie-estudos.ucdb.br/serieestudos/article/view/564. Acesso em: 10 maio 2020. 